\title{
Da Responsabilidade do Prefeito pela Prestação de Contas
}

Raul Armando Mendes Secretário-Geral do Ministério da Justiça

SUMÁRIO: 1) Considerações Preliminares; 2) A obrigatoriedade de prestar contas na forma da lei; 3) Os requisitos da prestação de contas; 4) A não prestação de contas; 5) O controle externo; 6) O prazo para a apreciação das contas; 7) O Crime de responsabilidade; 8) A infração politico-administrativa; 9) As contas do Prefeito nomeado; 10 Considerações finais.

\section{CONSIDERAÇõES PRELIMINARES}

Ao contrário do que muitos pensam, o Município brasileiro não integra o nosso regime federativo. A vigente Constituição diz, em seu artigo $1 .^{\circ}$ que o "Brasil é uma República Federativa, constituída, sob o regime representativo, pela união indissolúvel dos Estados, do Distrito Federal e dos Territórios". O Município não está nesse elenco, logo, não é uma entidade federativa. Não obstante, sua posição é singularíssima. O Município é uma circunscrição territorial dos Estados, criado por lei (art. 14), pessoa jurídica de direito público interno, com autonomia constitucionalmente assegurada.

A autonomia municipal brasileira esteia-se na eletividade do Prefeito, Vice-Prefeito e Vereadores à Câmara Municipal; pela auto-administração, respeita o seu peculiar interesse, especialmente quanto:

a) à decretação e arrecadação dos tributos de sua competência e aplicação de suas rendas, sem prejuízo da obrigatoriedade de prestar contas e publicar balancetes nos prazos fixados em lei; e 
b) à organização dos serviços públicos locais.

São esses os princípios básicos da autonomia constitucional, que se pode sintetizar como governo próprio e competências privativas.

Autonomia significa autogoverno ou poder de gerir seus próprios negócios, dentro daquilo que for estabelecido, em lei, pela entidade superior, no caso o Estado, como se infere no artigo 13 da Constituição no texto decorrente da Emenda Constitucional $n .{ }^{\circ}$, de 29/10/1969.

No Rio Grande do Sul, a Constituição Estadual de 27 de janeiro de 1970 diz que os Municípios se regem pelas Leis Orgânicas e demais leis que adotarem, respeitados os princípios estabelecidos na Constituição Federal e na do Estado (art. 143).

A disposição citada não tem rigor constitucional. A nossa Lei Magna dá ao Estado o poder de auto-organizar-se, no que está incluída a criação de Municípios.

A auto-organização municipal gaúcha é, até certo ponto, ilusória, pois do artigo 143 até o artigo 159, o diploma estadual traça lineamentos dessa organização, além de mandar respeitar a Constituição Federal nos seus princípios básicos. Ora, traçando o Constituinte estadual os limites da organização municipal e a Lex Fundamentalis sendo respeitada nos seus princípios, pouco sobra ao Município para auto-organizar-se. As Cartas próprias do Rio Grande do Sul reserva-se a auto-administração no que concerne ao peculiar interesse da entidade do Estado. Muita coisa pode ficar reservada para constar das singulares Cartas-próprias, dentre elas os prazos e outros requisitos mínimos para os responsáveis prestarem contas de sua gestão financeira.

\section{A OBRIGATORIEDADE DE PRESTAR CONTAS NA
FORMA DA LEI}

Está erigida em princípio constitucional a obrigatoriedade de todo administrador prestar contas de sua gestão financeira. Uma das facetas da autonomia municipal é a aplicação de rene publicar balancetes nos prazos fixados em lei (art. 15, II, "a"). 
Nem mesmo nos Municípios estâncias hidrominerais ou declarados de interesse da segurança nacional, o Prefeito fica desobrigado de prestar contas. Isso porque a autonomia municipal sofre arranhões apenas no que respeita à eletividade para a curul governamental. No mais ela fica íntegra. E os responsáveis são obrigados a prestar contas, sob as penas da lei.

A atual Constituição mineira diz competir ao Prefeito encaminhar as contas da administração à Câmara Municipal até o dia 15 (quinze) de março de cada ano (art. 177,V). A Lei Orgânica paulista obriga o Prefeito a encaminhar ao Tribunal de Contas competente, até o dia 31 de março de cada ano, a sua prestação de contas e a da Mesa da Câmara, bem como os balanços do exercício findo (art. 39, X, do Decreto-lei estadual n. 9 , de $31 / 12 / 69$ ).

A Constituição gaúcha não tem disposição expressa quanto ao prazo para o Prefeito cumprir o mandamento constitucional da prestação de contas dos responsáveis. Remete a disciplinação à Lei Orgânica. No artigo 157 estão fixadas somente as atribuições privativas, tais como: $\mathrm{I}$ - a iniciativa de leis orçamentárias e que criem ou aumentem a despesa pública; II propor a criação de cargos e funções, com os respectivos estipêndios, e provê-los, salvo os da Secretaria da Câmara; III vetar projetos de lei; IV - prestar as informações solicitadas pela Câmara referente aos negócios públicos do Município; e V - convocar extraordinariamente a Câmara, quando o interesse da administração o exigir.

\section{OS REQUISITOS DA PRESTAÇÃO DE CONTAS}

As Constituições estaduais ou as leis orgânicas não disciplinam a maneira de fazer a prestação de contas. Esta ficou para as leis pertinentes, notadamente a Lei n. $4.320 / 64$ - Estatui normas gerais de Direito Financeiro para a elaboração e controle dos orçamentos e balanços da União, dos Estados, dos Municípios e do Distrito Federal - que se enquadra na Competência da União, consoante o artigo $8 .^{\circ}$, XVII, letra "c", da EC-n. 1/69.

Algumas leis estaduais traçaram normas para a prestação de contas, como é o caso da Lei mineira $n .^{\circ} 888$, de 12 de agosto de 1962, que já determinava a apresentação da comprovação dos gastos do exercício financeiro à Câmara Municipal, acom- 
panhada de um relatório da administração da municipalidade e mais os sequintes documentos:

1) balanço de receita e despesa;

2) quadro comparativo da receita orçada com a arrecadada e da despesa autorizada com a realizada;

3) demonstração sintética da execução orçamentária;

4) demonstração das operações de crédito;

5) demonstração discriminada da despesa realizada pela verba de Serviço de Obras Públicas;

6) balanço da receita e da despesa do Município, por distrito;

7) balanço do ativo e passivo;

8) demonstração da divida fundada;

9) demonstração das variações patrimonais;

10) demonstração discriminada da dívida flutuante;

11) inventário geral;

12) quadro comparativo do balanço patrimonial do exercício encerrado com o exercício anterior.

O Professor Clovis Gloeden, em seu trabalho "Manual da Contabilidade Municipal" - pág. 182 - Ed. SENAM/62 ensina: "A prestação de contas tem por fim demonstrar, no final de cada exercício financeiro, o resultado do trabalho desenvolvido durante o mesmo e dela se fará a análise quanto ao aspecto
moral e técnico".

A Lei n. $4.320 / 64$ exige que a prestação de contas seja feita dentro de seus preceitos.

A prestação de contas conterá :

Relatório das atividades do exercício financeiro;

1 - Demonstrativo da Execução Orçamentária;

II - Balanço Patrimonial;

III - Demonstração das Variações Patrimoniais; e

IV - Balanço Financeiro.

A prestação de contas do Prefeito à Câmara deverá englobar toda a atividade financeira, quer dos recursos próprios, quer dos provindos de outras entidades estatais, como o Fundo de de Energia Elétrica, Fundo de Minerais do País. 
O Centro de Estudos e Pesquisas de Administração Municipal - CEPAM - da Secretaria do Interior do Estado de São Paulo - elaborou excelentes roteiros sobre a prestação de contas dos mencionados fundos.

\section{A NÃO PRESTAÇÃO DE CONTAS}

As legislações estaduais ou mesmo as municipais não dizem expressamente qual a providência de ordem administrativa a ser adotada no caso de o Prefeito não prestar contas no prazo legal. Mais adiante veremos que a omissão constitui crime de responsabilidade e infração político-administrativa, do Decreto-lei n. 201/67. Agora nos interessa a parte formal.

Se o Prefeito não prestar contas, a posição mais consentânea será a de a Câmara nomear uma comissão para proceder "exofficio", à tomada de contas. Como as Câmaras de pequenos Municípios, na mor das vezes não têm serviços próprios de contabilidade, a dificuldade poderá ser superada usando-se, analogicamente, o artigo 81 , § $2 .^{\circ}$, da Lei $n . .^{\circ} 4.320 / 64$, assim: "Quando, no Município, não houver Tribunal de Contas ou órgão equivalente, a Câmara de Vereadores poderá designar peritos contadores para verificarem as contas do Prefeito e sobre elas emitirem parecer".

Podendo a Câmara contratar ou designar peritos para opinar sobre as contas apresentadas, muito maior razão terá para adotar idêntica providência quando for o caso de tomar as contas do administrador desidioso.

Tomadas as contas, na forma acima aventada, a Câmara as remeterá ao Tribunal de Contas do Estado ou órgão estadual a que for atribuída essa incumbência, já que a qualquer deles compete, como auxiliar, o exercício do controle externo.

\section{O CONTROLE EXTERNO}

O controle da execução orçamentária, pelo Poder Legislativo, terá por objetivo verificar a probidade da Administração, a guarda e legal emprego dos dinheiros públicos e o cumprimento da Lei Orçamento (art. 81 da Lei n..$^{\circ}$ 4.320/64). No artigo 82 , do citado diploma, estabëlece-se a obrigatoriedade de 0 Poder Executivo, anualmente, prestar contas ao Poder Legislativo, no prazo estabelecido nas Constituições e nas Leis Orgânicas dos Municípios. 
Essas contas serão submetidas às Câmaras Municipais, com parecer prévio do Tribunal de Contas ou órgão equivalente. Quando, no Município, não houver Tribunal de Contas ou órgão equivalente, a Câmara de Vereadores poderá designar peritos contadores para verificarem as contas do Prefeito e sobre elas emitirem parecer.

Nesta parte, típica do controle externo, a Lei n. $4.320 / 64$ está revogada. A Lei Maior alterada pela Emenda Constitucional n. $1 / 69$ enuncia outra regra, a saber: "O controle externo da Câmara Municipal será exercido com o auxílio do Tribunal de Contas do Estado ou órgão estadual a que for atribuída essa incumbência (art. $16, \S 1 \%^{\circ}$ ).

O parecer do Tribunal de Contas do Estado do órgão competente vincula a decisão da Câamara na apreciação das contas do Prefeito. Somente por decisão de dois terços dos membros da Câmara Municipal deixará de prevalecer o parecer prévio, emitido pelo Tribunal de Contas ou órgão estadual competente, sobre as contas que o Prefeito deve prestar anualmente (art. 16, § 2. ${ }^{\circ}$ da EC-n.* 1/69).

A decisão da Câmara que rejeitar o parecer do Tribunal de Contas estadual, favorável ou contrário às contas do Prefeito, há de ser fundamentado. Como nem sempre a Câmara está tecnicamente capacitada a emitir parecer sobre as contas, pode valer-se do disposto na parte final do artigo $81, \S 2 .^{\circ}$, da Lei $n .^{\circ} 4.320 / 64$.

A Lei Orgânica de São Paulo diz que rejeitadas as contas serão imediatamente remetidas ao Ministério Público para os devidos fins. Obviamente os devidos fins é o oferecimento da denúncia, por crime de responsabilidade, nos termos do Decreto-lei' n. $201 / 67$.

\section{O PRAZO PARA APRECIAÇÃO}

Já vimos que o Chefe da Administração Municipal tem prazo para encaminhar suas contas à Câmara. Variando de dias. ele, geralmente, expira no mês de março.

A Constituição gaúcha não fixa prazo. A matéria deve ser regulada pelas Cartas-próprias. 
Como o Prefeito tem prazo para apresentar suas contas, a Câmara também tem para aprová-las. Assim é que a lẹgislação paulista estabeleceu que, decorridos trinta dias sem deliberação, as contas serão consideradas aprovadas ou rejeitadas, de acordo com a conclusão do parecer do Tribunal de Contas.

E claro que se o Tribunal de Contas ou o órgão estadual equivalente houver concluído, no seu parecer prévio, pela re. jeição das contas, estas, independentemente de qualquer manifestação do plenário da Câmara, deverão ser remetidas ao Ministério Público local. A omissão da Câmara, seja qual for o motivo determinante, não é vara de condão para irresponsabilizar o administrador claudicante.

Comumente nota-se, no interior brasileiro, que as Câmaras não se reunem por falta de "quorum". Mas isso igualmente não justifica a eternização da não aprovação das contas do Prefeito. O problema se afigura mais grave quando as contas houverem sido rejeitadas pelo Tribunal de Contas. Neste caso, o Presidente da Edilidade ou qualquer Vereador poderá pedir sejam as contas endereçadas ao membro do Ministério Público local. Se a providência não for adotada, o Promotor Público deverá avocar o processo, para os fins devidos. Não se compreende que a desídia de uns, os interesses políticos de outros constituam motivo para a não responsabilização daquele que devia cuidar com lisura dos dinheiros públicos.

\section{O CRIME DE RESPONSABILIDADE}

Os crimes de responsabilidade do Prefeito estão definidos no artigo $1 .^{\circ}$ do Decreto-lei $n .^{\circ} 201$, de 27 de fevereiro de 1967. "Quase todos eles - diz JOSÉ AFONSO DA SILVA, "in" O Prefeito e o município - pág. 92 - ed. SERFHAU - objetivam a tutela jurídica da administração pública municipal, no que concerne à preservação do patrimônio público e do interesse patrimonial do Município, e, ainda, à fidelidade e probidade dos agentes do poder público. O sujeito ativo, claro, é o Prefeito mas sendo esta qualidade do agente elementar ao crime, comunica-se aos co-autores, que, conquanto, não sejam funcionários, responderão pelo mesmo delito (artigo 26 do Código Penal). Sujeito passivo é o Município, quase sempre, ou seja, a Administração pública municipal. A materialidade do fato consiste em variados tipos de ação, conforme se enumera a seguir, e está representada pelos verbos, que constituem núcleos 
do tipo delituoso. $\mathrm{O}$ elemento subjetivo, quase sempre se manifesta do dolo genérico: vontade dirigida à prática de qualquer das ações incriminadas".

O primeiro dos crimes enunciados no art. $1^{\circ}$ é o peculato, do artigo 313, do Código Penal.

É objeto deste estudo o crime definido no inciso VI, do artigo 1. , assim: "Deixar de prestar contas anuais da administração financeira do Município à Câmara de Vereadores, ou ao órgão que a Constituição do Estado indicar, nos prazos e condições estabelecidos". (sem grifo no original).

O crime é de ação pública, acarretando para o autor pena de detenção, de três meses a três anos. O Promotor inicia a ação penal. Não importa se o agente passivo da relação processual está ainda no exercício do cargo. O "initio litis" independe de qualquer pronunciamento da Câmara de Vereadores.

Se a condenação definitiva alcançar o titular do mandato, quer no exercício ou não, mas dentro do prazo de sua duração, acarreta-lhe, além da condenação à pena privativa de liberdade, a perda do mandato conseqüente do cargo e a inabilitação, pelo prazo de cinco anos, para o exercício de cargo ou função pública, eletiva ou de nomeação, sem prejuízo da reparaçãao civil do dano causado ao patrimônio público ou particular.

O processo do crime de responsabilidade está definido no artigo $2 .^{\circ}$ do mencionado diplọma legal. O Código de Processo Penal lhe é subsidiário.

\section{A INFRAÇÃO POLITICO-ADMINISTRATIVA}

A falta de prestação de contas também tipifica infração político-administrativa. É o caso de praticar, contra expressa disposição de lei, ato de sua competência ou omitir-se na sua prática.

Como já vimos, a lei obriga ao Poder Executivo, anualmente, prestar contas ao Poder Legislativo. Se o Prefeito se omite nessa prática comete infração poli-
tico-administrativa. As infrações político-administrativas são sancionadas com a cassação do mandato. A Câmara de Vereadores compete apurar e julgar. O Art. $50^{\circ}$ do Decreto-lei ...... n. $201 / 67$ disciplina o processo, se outro não for o rito estabelecido pela lei estadual. 


\section{AS CONTAS DO PREFEITO NOMEADO}

O Prefeito nomeado, quer para a estância hidromineral ou para Município declarado de interesse da segurança nacional, também poderá incidir na infração prevista no art. $4 .^{\circ}$, VII sem embargo dos demais. No entanto a Câmara não pode sancionar o autor com a perda do cargo, que, na espécie, seria demissão. O Prefeito não tem mandato. É agente de confiança do Governador ou do Presidente da República. Sua permanência no exercício do cargo se prolongará enquanto bem servir aos interesses da administração estadual ou federal; neste caso leva-se em conta a segurança nacional.

Elaborado o processo e evidenciada a culpa, cumpre à Câmara de Vereadores representar à autoridade nomeante - 0 Governador do Estado - para as providências cabíveis, ou seja a exoneração ou destituição do Prefeito. Mas a decisão final cabe àquela autoridade, que poderá, inclusive, proceder às sindicâncias capazes de melhor esteiar uma tomada de posição relativa à conduta do Prefeito.

\section{CONSIDERAÇõES FINAIS}

Como vimos, a prestação de contas é corolário de toda gestão de dinheiros públicos. Nos países ela tem a respeitabilidade de obrigação constitucional. Todo administrador deve prestar contas, não só dos dinheiros que manipula, como de seus demais atos. Não são só as Câmaras Municipais e os Tribunais de Contas agentes fiscalizadores do emprego ou da boa aplicação dos recursos públicos. A Constituição Federal dá a qualquer cidadão a legitimidade para propor ação que vise a anular $o$ ato e responsabilizar o administrador e os seus beneficiários, cuja conduta implicar em lesão ao patrimônio de entidades públicas (art. 153, § 31). Nesse passo é lapidar a lição de HELY LOPES MEIRELLES ("in" Direito Administrativo Brasileiro, ed. RT/66, pág. 582): "É um instrumento de defesa dos interesses da coletividade, utilizável por qualquer de seus membros. Por ela não se amparam direitos próprios, mas sim direitos da comunidade. $\mathrm{O}$ beneficiário direto e imediato desta ação não é o autor; é o povo, titular do direito subjetivo ao governo honesto". 
